\title{
Doctor of Public Health
}

National Cancer Institute

\section{Source}

National Cancer Institute. Doctor of Public Health. NCI Thesaurus. Code C39390.

Doctor of Public Health is an academic degree in public health. The prior degree is generally earned in the closely related professional field, e.g. medicine. 